\title{
Pericarditis and myocarditis in farmed Atlantic halibut Hippoglossus hippoglossus
}

\author{
R. Johansen ${ }^{1, *}$, T. Poppe ${ }^{2}$ \\ ${ }^{1}$ National Veterinary Institute, PO Box 8156 Dep., 0033 Oslo, Norway \\ ${ }^{2}$ Norwegian School of Veterinary Science, PO Box 8146 Dep., 0033 Oslo, Norway
}

\begin{abstract}
Farming of Atlantic halibut Hippoglossus hippoglossus is a growing industry in Norway. This study comprises the first description of heart morphology in fish from one Atlantic halibut farm. Fish with no clinical signs of disease were randomly sampled ( 8 to 12 mo old, weight 1 to $50 \mathrm{~g}$ ). The hearts were studied by light and electron microscopy and samples were taken from the kidney and pericardial cavity for bacteriological examination. Slight to severe changes were found in most hearts at all samplings. The most serious pericardial and myocardial changes were seen in larger fish (15 to $50 \mathrm{~g}$ ). In some of the hearts the affected pericardium formed multifocal protrusions. Eight fish had an adhesion between the apex of the ventricle and the parietal wall of the pericardial cavity. Results of bacteriology and immunohistochemistry investigations for common disease agents were negative.
\end{abstract}

KEY WORDS: Atlantic halibut - Hippoglossus hippoglossus · Heart · Pericarditis · Myocarditis · Histopathology · Immunohistochemistry $\cdot$ Ultrastructure

Resale or republication not permitted without written consent of the publisher

Halibut farming is a new fast-growing industry in Norway. There have been only a few studies on the anatomy and general pathology of these farmed fish (Pittman 1991, Kjørsvik 1992). In addition, none of the studies on wild caught halibut have focused on the heart (Schmidt 1904, Tåning 1936, Haug et al. 1989). So far, infectious diseases like infectious pancreatic necrosis virus (IPNV), nodavirus infection and vibriosis have been the main focus for disease research in farmed Atlantic halibut (Biering 1997, Bricknell et al. 2000, Grotmol 2000). Of these, only nodavirus infection has been described to infect hearts of Atlantic halibut (Grotmol et al. 1997).

The pericardium is a 2-layered fibro-serous sac enclosing the heart and lining the pericardial cavity. The serous layer lining the pericardial cavity consists of a

*E-mail: renate.johansen@vetinst.no single sheet of squamous epithelial cells that secrete pericardial fluid. This serous pericardial fluid lubricates the cavity and allows the heart to move freely. The fibrous layer beneath the layer of epithelial cells consists of loose connective tissue, adipocytes, nerves and coronary vasculature. The fibrous layer thickens with age due to an increase in collagen bundles (Santer 1985). In the majority of teleosts (exceptions are European eel Anguilla anguilla and blue marlin Makaira ampla) the heart lies free of attachments in the pericardial cavity (Santer 1985).

The teleost myocardium consists of an inner spongiform layer and an outer compact layer. In actively swimming fish, like salmonids, the compact outer myocardium is thick and well developed, while flatfishes, like Atlantic halibut, hardly have any compact layer (Ferguson 1989). The thickness of the compact layer may also show significant variation with the habitat and life style of the fish. Lake-dwelling rainbow trout Oncorhynchus mykiss have a thinner compact layer than anadromous populations (Graham \& Farrell 1992). Farming environments may, therefore, change the life and heart condition of fish. In Norway several pathological conditions, including malformations, have been reported from hearts of farmed salmonids (Amin \& Poppe 1989, Ferguson et al. 1990, Poppe et al. 1998, 2002, Poppe \& Taksdal 2000). Steatitis of epicardial fat of farmed white sturgeon Acipenser transmontanus has been reported and a possible nutritional imbalance linked to oxidised fat intake are discussed as a possible cause (Guarda et al. 1997). The affected epicardia of the sturgeon had high levels of fat and showed focal lesions with lymphocyte infiltrates.

The aim of this study was to investigate the condition of the heart in farmed Atlantic halibut and describe any pathological change. Pericarditis and myocarditis were identified, and possible causes were investigated. 
Materials and methods. Fish rearing and sampling: Eggs from several spawners were hatched during March 2000. Fish were sampled unevenly from November 2000 to March 2001. All fish were of the same age at the times of sampling, but their weight varied from 1 to $50 \mathrm{~g}$ at all samplings. The fish were categorised into 2 groups, one of small fish (1 to $10 \mathrm{~g}$ ) with poor appetite and one of larger fish (15 to $50 \mathrm{~g}$ ) that were growing normally.

At first feeding the larvae were fed locally harvested zooplankton and enriched Artemia for $40 \mathrm{~d}$ before being weaned to commercial dry pelleted feed. The water temperature was 10 to $11^{\circ} \mathrm{C}$ and algae were added to the water to make it green during this period (Planas \& Cunha 1999). Green algae water has been shown to give better feeding results than clear water at this halibut farm.

Histopathology: Hearts and other organs (gill, liver, spleen, kidney, intestine, muscle and skin) from 30 fish were fixed for at least $24 \mathrm{~h}$ in neutral phosphatebuffered $10 \%$ formalin. Standard procedures for processing for light microscopy were followed. Sections were cut and stained with haematoxylin and eosin (H\&E). Hearts with severe changes were further stained with Ziehl Neelsen, Giemsa, Gram, van Gieson, and Martius Scarlet blue (MSB)/trichrome (Bancroft \& Stevens 1990).

Immunohistochemistry (IHC): Paraffin-embedded organs were examined with antisera against a range of the most common pathogens affecting farmed salmonids, i.e. Vibrio salmonicida, Listonella anguillarum (O1/O2), Aeromonas salmonicida, Yersinia ruckeri (I, II, III), IPNV and viral haemorrhagic septicaemia virus (VHSV). Sections were also tested with antiserum raised against nodavirus originally isolated from Atlantic halibut (Dannevig et al. 2000). The IHC technique briefly involves pre-treatment with trypsin or in a microwave oven and/or blocking of non-specific antibody binding sites with bovine serum albumin in Tris-buffered saline ( $\mathrm{pH}$ 7.4). Primary and secondary anti-sera were then added before streptavidinalkaline-phosphate complex and fast red substrate were used (Polak \& Noorden 1997).
Bacteriology: Smears from 10 kidneys and 5 pericardial cavities were aseptically streaked onto heart infusion agar (Difco), with $5 \%$ bovine blood $(+0.5$ or $2 \% \mathrm{NaCl}$ ) and incubated aerobically and anaerobically at 10,15 and $22^{\circ} \mathrm{C}$.

Electron microscopy: Six hearts were fixed in 3\% glutaraldehyde in a $0.1 \mathrm{M}$ cacodylate buffer, $\mathrm{pH}$ 7.4. The samples were then rinsed in cacodylate buffer, postfixed in $1 \%$ osmium tetroxide, dehydrated in ethanol and embedded in LX112. Ultrathin sections were stained with uranyl acetate and lead citrate and examined in a Philips 208S transmission electron microscope.

Results. Macroscopic observations: The mortality rate was low and no signs of disease were observed at the fish farm.

Seven of the sampled fish were only about $1 \mathrm{~g}$ and therefore fixated whole, so the hearts of these fish were not examined macroscopically. The remaining 29 hearts showed no macroscopic abnormalities except for an adhesion observed in 8 fish between the heart and the pericardial wall along the ventricle apex (Fig. 1). Most attachments broke easily on removal of the hearts from the pericardial cavity, while some attachments were more firm. It is possible that some attachments were so loose that they were not detected.

Histopathology: In the group of small fish $(\mathrm{N}=10$, 1 to $10 \mathrm{~g}$ ) only 1 fish had pericarditis, whereas 18 of the larger fish $(\mathrm{N}=20,15$ to $50 \mathrm{~g})$ displayed sparse to extensive pericarditis (Table 1). The frequency and severity of the findings appeared constant during the 4 mo of sampling.

The affected pericardium had slight to severe thickening due to hyperplasia of a variety of pleomorphic cells in the fibrous layer. The thickened parts protruding into the cavity were often multifocally arranged, and the majority of the cells in the affected areas stained dark basophilic with H\&E staining (Fig. 2). Many of the cells in the thickened pericardium were leukocyte-like, often with a bean-shaped nucleus. Red blood cells were also seen scattered throughout the affected tissue. The inner serous layer of the pericardium formed a single-layer of cubic epithelium in

Figs. 1 to 6. Hippoglossus hippoglossus. Atrium (A), ventricle (V), bulbus arteriosus (B), pericardial wall (W), pericardium (P), myocardium (M). Fig. 1. Heart of an 11 mo old halibut. A needle was used to demonstrate the adhesion between the apex of the ventricle (V) and the pericardial wall (W) (arrow). Fig. 2. Focal protrusion of the visceral pericardium (P) from a $9 \mathrm{mo}$ old, $30 \mathrm{~g}$ fish, H\&E staining. Note the cubic serous layer of the pericardium (arrowhead). Hypercellularity is also seen in the myocardium (M) underneath the affected pericardium. Scale bar $=100 \mu \mathrm{m}$. Fig. 3. Heart from a 12 mo old fish $(50 \mathrm{~g})$ with severe pericarditis (arrowheads) and myocarditis (arrows). H\&E staining. Scale bar $=\overline{1 \mathrm{~mm}}$. Fig. 4. Higher magnification of the infected pericardium in Fig. 3. The inner squamous layers of both visceral and parietal pericardium were almost absent (arrowheads). Van Gieson staining shows red staining of connective tissue in the wall of the cardiac cavity and in the lining of myocardium (M), but no staining of the cells in the pericardium $(\mathrm{P})$. Scale bar $=50 \mu \mathrm{m}$. Fig. 5. Section of a heart from a 12 mo old fish $(50 \mathrm{~g})$ with adhesion between the ventricle $(\mathrm{V})$ and the pericardial wall (W) (arrow). H\&E staining. Scale bar $=1 \mathrm{~mm}$. Fig. 6. Higher magnification of the adhesion in Fig. 5 shows moderate pericarditis (P) and myocarditis $(\mathrm{M})$ around the attachment of loose connective tissue. H\&E staining. Scale bar $=200 \mu \mathrm{m}$ 


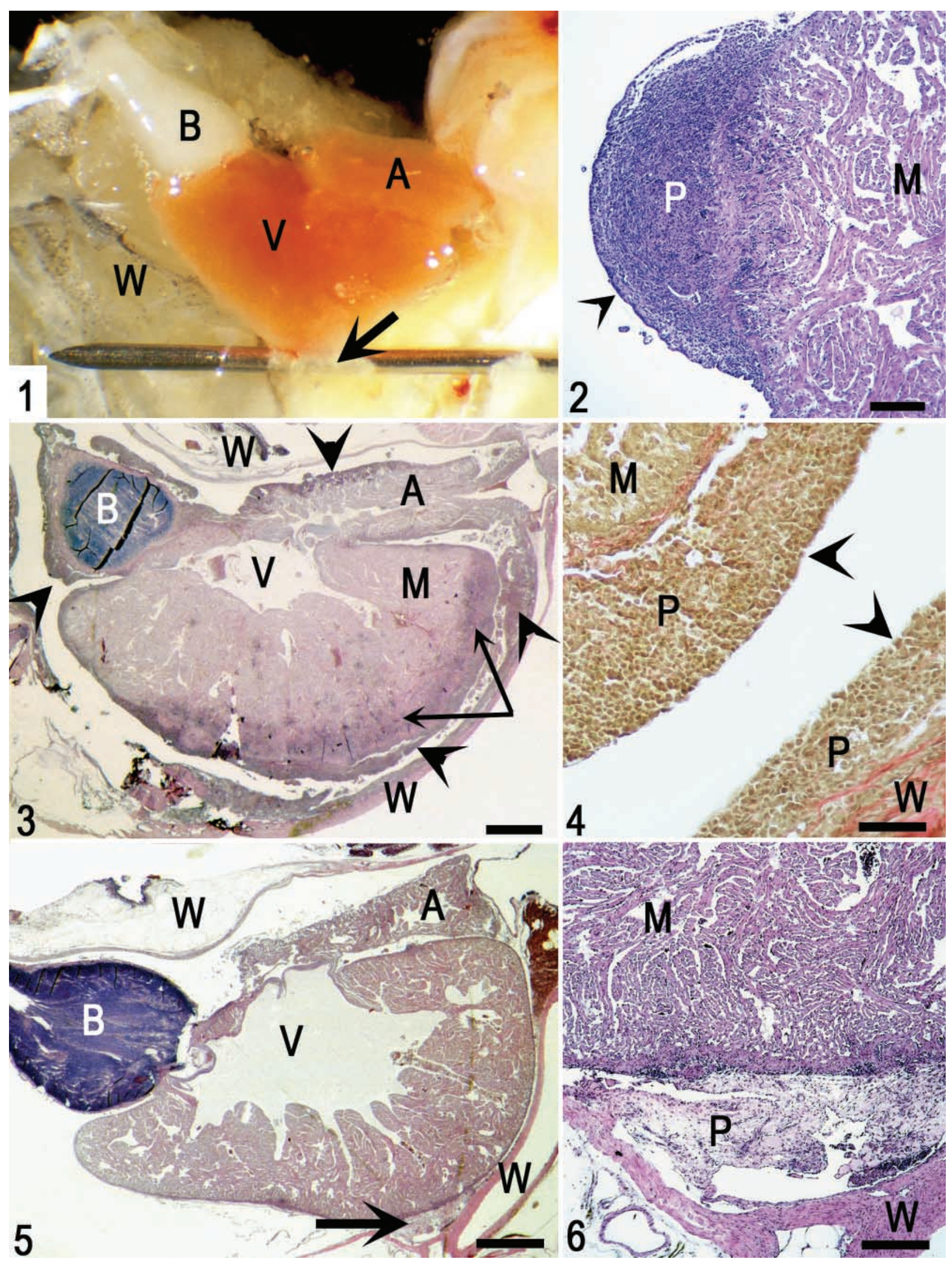


Table 1. Hippoglossus hippoglossus. Light microscopic study of hearts of farmed Atlantic halibut. Number of fish with degrees of changes in the pericardium

\begin{tabular}{|lcccc|}
\hline & $\begin{array}{c}\text { No } \\
\text { pericarditis }\end{array}$ & $\begin{array}{c}\text { Slight } \\
\text { pericarditis }\end{array}$ & $\begin{array}{c}\text { Moderate } \\
\text { pericarditis }\end{array}$ & $\begin{array}{c}\text { Extensive } \\
\text { pericarditis }\end{array}$ \\
\hline $\begin{array}{l}\text { Small fish } \\
1-10 \mathrm{~g}(\mathrm{~N}=10)\end{array}$ & 9 & 0 & 0 & 1 \\
$\begin{array}{l}\text { Large fish } \\
15-50 \mathrm{~g}(\mathrm{~N}=20)\end{array}$ & 2 & 10 & 4 & 4 \\
\hline
\end{tabular}

some of the affected areas (Fig. 2). The most extensively affected hearts had severe hyperplasia of pericardium and leukocyte-like cells in the pericardial cavity (Fig. 3). The squamous layer was in some places totally absent (Fig. 4). The cells of the affected pericardium and in the pericardial cavity stained negatively for connective tissue (van Gieson and MSB trichrome) (Fig. 4). Leukocyte-like cells also invaded the myocardium underneath the most severely affected pericardium and myocard degeneration was seen in some locations (Fig. 2). Hyperplasia and hypertrophy of the endocardium was observed in affected areas. The less affected hearts often had an adhesion to the pericardial wall at the ventricle apex (Figs. $5 \& 6$ ).

Heart sections with acute severe changes were stained with special staining techniques to reveal bacteria (Gram, Giemsa and Ziehl Neelsen), but no bacteria were found. No pathological changes were seen in other tissues examined.

Immunohistochemistry: There was no evidence of infection with Vibrio salmonicida, Listonella anguillarum (O1/O2), Aeromonas salmonicida, Yersinia ruckeri (I, II, III), IPNV, VHSV or nodavirus in fish with severe pericarditis.

Bacteriology: All 10 kidneys tested for bacteria were negative. Of the 5 smears from pericardial cavities 2 resulted in isolation of a mixed bacterial population. The pericardial cavities of these fish were small and the smears were possibly contaminated during sampling. Later microscopy of the same fish revealed that all tested hearts showed pericarditis.

Electron microscopy: The visceral pericardium from fish with and without pathological change was examined. Unaffected pericardium was 1 to 2 cell layers thick while affected pericardium consisted of several layers of large pleomorphous leukocyte-like cells. Infectious agents were not observed.

Discussion. This study shows that farmed Atlantic halibut might have severe pathological changes in the heart and pericardial cavity without showing clinical signs of disease. The adhesion of the heart to the pericardial wall reported in this paper may restrict the heart from moving freely and thereby reduce cardiac output. Signs of pericarditis might not be observed under normal farming circumstances, but fish with pericarditis might be more susceptible to stress and diseases.

There are 3 main shapes of teleost ventricle: saccular, tubular and pyramidal (Sanchez-Quintana et al. 1995). The ventricle of the Atlantic halibut has a pyramidal shape and the apex is located ventrally in the pericardial cavity (Fig. 1). As the halibut swims with the right side up, this means that the apex is oriented horizontally, not vertically as in most species. This fact might make flatfish more susceptible to pericardial problems than other fish species when farmed under sub-optimal conditions.

Wild halibut spawn in deep waters and the eggs and larvae drift around for 1 to 2 mo in these cold, dark clean waters before they start feeding on zooplankton. Large dark silos are used at the halibut farms to mimic these conditions. Live wild-caught zooplankton have so far been necessary as a first feed, and the larvae are weaned to dry commercial pelleted feed at about 4 mo of age. Malformations like lack of pigmentation, lack of eye metamorphosis and lack of ability to close the jaws have been reported in halibut farms, and are believed to be due to sub-optimal farming and feeding conditions (Pittman 1991, Morrison \& MacDonald 1995, Bolker \& Hill 2000). Aspects of farming conditions like low water level, sub-optimal nutrition, microbes or stress might also play a part in the development of pericarditis (Guarda et al. 1997).

Farming of juvenile Atlantic halibut is very difficult and accumulated mortality over $90 \%$ during the first $100 \mathrm{~d}$ following hatching is common. The sampled fish were of the same age at the time of sampling but weight varied from 1 to $50 \mathrm{~g}$ at all samplings. Weight differences like these are common in halibut farming. Some fish do not start feeding or have a poor appetite, and even amongst those fish with good appetite, size differs significantly. Expected growth rates for Atlantic halibut have not been established. Farmed Atlantic halibut normally rest on the bottom of the tank most of the time and this makes it difficult to monitor sick fish with reduced activity or lack of appetite. Pathological conditions might be overlooked because of the expected high mortality, lack of expected growth rate and difficulties in monitoring abnormal behaviour.

The fact that the group of larger fish was more affected with pericarditis and myocarditis than the smaller fish indicates that dietary factors might play an important role. Pathological conditions due to malnutrition, toxic components and changes in the redoxbalance are known to occur in other species of farmed 
fish (Ferguson 1989, Guarda et al. 1997, Planas et al. 1999). Further investigations are needed to find the cause, prevalence and importance of pericarditis in farmed Atlantic halibut. Chemical and toxic investigations are needed along with further search for infective agents. Fish welfare is an important factor in fish farming today and the ethical problem of rearing fish with heart problems has to be taken seriously. Pericarditis has also been observed in farmed Atlantic halibut in Iceland (Gísli Jonsson pers. comm.). An initiative has been taken to combine future research on this matter in our 2 countries.

Acknowledgements. Sincere thanks are due Duncan Colquhoun for doing the bacteriological work in this study and for correcting our English. Thanks are also due to Randi Terland, Else Engeland and Turid Haug for excellent technical assistance, and Dr Bjørn Gjerde for help with the photo images.

\section{LITERATURE CITED}

Amin AB, Poppe TT (1989) Subendocardial fibroelastosis in Atlantic salmon: a case report. Bull Eur Assoc Fish Pathol 9:86-87

Bancroft JD, Stevens A (1990) Theory and practice of histological techniques. Churchill Livingstone, Edinburgh

Biering E (1997) Infectious pancreatic necrosis virus infections of farmed Atlantic halibut. PhD thesis, University of Bergen

Bolker JA, Hill CR (2000) Pigmentation development in hatchery-reared flatfishes. J Fish Biol 56:1029-1052

Bricknell IR, Bowden TJ, Verner Jeffreys DW, Bruno DW, Shields RJ, Ellis AE (2000) Susceptibility of juvenile and sub-adult Atlantic halibut (Hippoglossus hippoglossus L.) to infection by Vibrio anguillarum and efficacy of protection induced by vaccination. Fish Shellfish Immunol 10: 319-327

Dannevig BH, Nilsen R, Modahl I, Jankowska M, Taksdal T, Press CM (2000) Isolation in cell culture of nodavirus from farmed Atlantic halibut Hippoglossus hippoglossus in Norway. Dis Aquat Org 43:183-189

Ferguson HW (1989) Cardiovascular system. In: Ferguson HW (ed) Systemic pathology of fish. Iowa State University Press, Ames, p 104-124

Ferguson HW, Poppe TT, Speare DJ (1990) Cardiomyopathy in farmed Norwegian salmon. Dis Aquat Org 8:225-231

Graham MS, Farrell AP (1992) Environmental influences on cardiovascular variables in rainbow trout, Oncorhynchus

Editorial responsibility: David Bruno,

Aberdeen, Scotland, UK mykiss. J Fish Biol 41:851-858

Grotmol S (2000) Nodavirus infections of farmed fish with emphasis on Atlantic halibut, Hippoglossus hippoglossus L. $\mathrm{PhD}$ thesis, University of Bergen

Grotmol S, Totland GK, Thorud K, Hjeltnes BK (1997) Vacuolating encephalopathy and retinopathy associated with a nodavirus-like agent: a probable cause of mass mortality of cultured larval and juvenile Atlantic halibut Hippoglossus hippoglossus. Dis Aquat Org 29:85-97

Guarda F, Bertoja G, Zoccarto I, Tartari E, Biolatti B (1997) Spontaneous steatitis of epicardial fat in farmed white sturgeon Acipenser transmontanus. Aquaculture 158: $167-177$

Haug T, Kjørsvik E, Pittman K (1989) Obervations on a wild Atlantic halibut larva (Hippoglossus hippoglossus). J Fish Dis 34:799-801

Kjørsvik E (1992) Histomorphology of the early yolk-sac larvae of the Atlantic halibut (Hippoglossus hippoglossus L.) - an indication of the timing functionality. J Fish Biol 41:1-19

Morrison CM, MacDonald CA (1995) Normal and abnormal jaw development of the yolk-sac larva of Atlantic halibut Hippoglossus hippoglossus. Dis Aquat Org 22:173-184

Pittman K (1991) Aspects of the early life history of the Atlantic halibut, Hippoglossus hippoglossus. PhD thesis, University of Bergen

Planas M, Cunha I (1999) Larviculture of marine fish: problems and perspectives. Aquaculture 177:171-190

Polak JM, Noorden S (1997) Introduction to immuncytochemistry. Springer-Verlag, New York

Poppe TT, Taksdal T (2000) Ventricular hypoplasia in farmed Atlantic salmon Salmo salar. Dis Aquat Org 42:35-40

Poppe TT, Johansen R, Tørud B (2002) Cardiac abnormality with associated hernia in farmed rainbow trout Oncorhynchus mykiss. Dis Aquat Org (in press)

Poppe TT, Midtlyng P, Sande RD (1998) Examination of abdominal organs and diagnosis of deficient septum transversum in Atlantic salmon (Salmo salar L.) using diagnostic ultrasound imaging. J Fish Dis 21:67-72

Sanchez-Quintana D, Garcia-Martinez V, Climent V, Hurle JM (1995) Morphological analysis of the fish heart ventricle: myocardial and connective tissue architecture in teleost species. Ann Anat 177:267-274

Santer RS (1985) Morphology and innervation of the fish heart. Adv Anat Embryol Cell Biol 1-100

Schmidt J (1904) On pelagic post-larval halibut. In: Reitzel CA (ed) Meddelelser fra Kommisionen for Havundersøgelser. Bianco Lunos BOGTRYKKERI, Copenhagen, p 1-15

Tåning ÅV (1936) On the eggs and young stages of the halibut. In: Reitzel CA (ed) Meddelelser fra Kommissionen for Danmarks Fiskeri- og havbruksundersøgelser. Bianco Lunos BOGTRYKKERI, Copenhagen, p 1-23

Submitted: November 25, 2001; Accepted: February 28, 2002 Proofs received from author(s): April 19, 2002 